\title{
The Reflections of Final Year Medical Students About Nursing Home: "Loneliness and Abandonment"
}

\author{
Huseyin Elbi ${ }^{1}$, Selim Altan ${ }^{2}$, Aynur Cakmakci Cetinkaya ${ }^{3}$, Suheyla Rahman ${ }^{4}$ \\ ${ }^{1}$ Department of Family Medicine, Manisa Celal Bayar University, Faculty of Medicine, Manisa, Turkey \\ ${ }^{2}$ Department of Medical History and Ethics, Manisa Celal Bayar University, Faculty of Medicine, Manisa, Turkey \\ ${ }^{3}$ Department of Nursing, Manisa Celal Bayar University, Faculty of Health Sciences, Manisa, Turkey \\ ${ }^{4}$ Department of Medical Education, Manisa Celal Bayar University, Faculty of Medicine, Manisa, Turkey
}

Corresponding Author:

Huseyin Elbi, MD

https://orcid.org/0000-0002-2955-5400

Department of Family Medicine,

Manisa Celal Bayar University,

Faculty of Medicine, Uncubozköy

Mahallesi, MCBÜ Sağlık Bilimleri

kampüsü, Mimar Sinan Blv. No: 173,

Yunusemre/Manisa 45030, Turkey

E-mail: hsynelbi1@hotmail.com

Received: April 26, 2019

Revised: May 10, 2019

Accepted: June 4, 2019
Background: Population aging is a global phenomenon with opportunities and challenges. The numbers and proportions of older people are increasing in almost every country. This study aimed to evaluate the perceptions of nursing homes among final-year medical students. Methods: This qualitative study used the word association test as a data collection tool to obtain the reflections regarding nursing homes among final-year students, and the concept of "nursing homes" was defined in face-to-face interviews of the volunteer students. Results: Analysis of data collected from 51 students regarding nursing homes resulted in five main categories (old age [frequency, $f=74$ ], positive affect emotions [ $f=66$ ], negative affect emotions [ $f=165]$, loneliness [ $f=75]$, and abandonment $[f=46]$ ) based on the reflections that the term "nursing home" evoked among the students. In the present study, the final-year students primarily used more negative expressions. Conclusion: Qualitative studies with students, such as those included in the present study, can provide important clues for the development of educational curriculum and social health policies. (Ann Geriatr Med Res 2019;23:77-82)

Key Words: Aged, Nursing home, Reflection, Student

\section{INTRODUCTION}

The term "aging" can be defined in several ways. The physiological condition of "being old" is related to the ability and speed of adaptation of an individual; as individuals age, their ability to adapt to situations and events decreases. This biological and psychological process, together with familial, social, and economic elements, has increasingly complex effects on the individual and society. While active, safe, and healthy aging people offer numerous opportunities to the society in which they live, aging presents social, economic, and cultural challenges to individuals, families, and society.

Population aging is a global phenomenon with opportunities and challenges. ${ }^{3)}$ The ratio of the aging population to the total population in Turkey increased from 3.4\% in 1955 to $8.5 \%$ in 2017 and is estimated to increase to $10.5 \%$ by $2030 .{ }^{4)}$ The global increase in aging populations is concentrated primarily in urban areas, with the increase in aging population in rural areas lower than that in urban areas. ${ }^{5)}$

In recent years in Turkey, the percentage of aging population residing in urban areas has increased significantly with the migration of individuals from rural to urban areas. ${ }^{6)}$ The consequences of the urbanization process include living in a nuclear instead of extended families and changes in the way of living and care for older people. The forms of urban housing, number and needs of traditional family members, and participation of both women and men in the workforce have increased the proportion of aging individuals who live alone. ${ }^{7,8)}$ There were 120 nursing homes in the early 2000s in Turkey, a number which increased to 367 in 2016. ${ }^{\text {9) }}$

Due to the strong family structure in our developing country, there are problems with the acceptance of nursing homes by society. Nursing homes are not a source of problems in industrialized modern societies. They are viewed as a natural part of life such as hospitals, sports clubs, restaurants, hotels, schools, etc. However, older people in Turkey tend to continue to live in the same house along with their children and grandchildren. While other family members generally think the same way, older adults are generally considered to be more comfortable in nursing homes due to realities such as the necessities of modern life, working life, gradually decreasing houses, communication problems, etc. In the solution of this problem, the role of physicians who have direct relationships with a large part of society should be investigated. ${ }^{10)}$ 
Physicians account for 50.8\% of "persons who can be influential in the decision of the older people to settle in the nursing home." ${ }^{11)}$ The opinions of the last-year students of medical faculties are particularly important because they will soon serve as physicians. They are also the representatives of a young generation of physicians. In this context, the aim of this study was to determine what final year students who would soon become medical professionals thought about the concept of "nursing homes." We believed that the reflections of young doctors on this topic could indicate how medical education curriculum regarding older people and aging should be changed.

\section{MATERIALS AND METHODS}

\section{Setting and Design}

This study is a conceptual analysis using the word association test (WAT) ${ }^{12)}$ to learn about the perspective of final year medical students regarding the concept of "nursing homes," which constitute an important aspect of old age. The WAT is a method commonly used in psychology to reveal an individual's private world. The association test is a way to identify the relational meaning of a stimulus word or the relationship between two stimulus words. These relationships reveal the verbal memories, thought processes, emotional states, and personalities of the participants. ${ }^{13)}$

The qualitative research model was used to analyze the reflections of the final year students regarding the concept of "nursing homes" in a realistic and holistic way. In qualitative research, which facilitates the learning of opinions and perceptions, a variety of data collection techniques, such as observation, interview, and document analysis, can be used. ${ }^{14)}$

\section{Selection of Participants}

In our medical school, all final year students are obliged to visit the same nursing home within the scope of the "Approach to Risk Groups” program (1 week), accompanied by a faculty member, and are informed about the demographic characteristics of aging and its effects on body systems to develop their abilities. In this study, students visited a single nursing home in a non-governmental organization. According to other several nursing homes in Turkey, the nursing home of this study was considered to be with good physical facilities and residents had good economic and educational level. Therefore, it is not foreseen that the opinions of the participating students about the nursing home would be weighted with negative reflections.

The study group consisted of students attending the final period of their medical curricula in 2016-2017 $(n=121)$. In order to avoid bias in the study, all students who completed the visit and volunteered were included in the study. After the data started to be repeated in the participating students (after 51 students), the study was terminated due to data saturation. Written approvals were obtained directly from the participants.

\section{Data Collection Tool and Technique}

The research involved the use of a unique data collection tool and technique. The WAT was used as the data collection tool and the concept of "nursing home" was defined using face-to-face interviewing methods among the volunteer students. The students were provided a blank piece of A4 paper and were asked to write the first three words that came to their minds when they heard the term "nursing home" and were also asked to write several sentences (experience, recipe, etc.) associated with each word.

To avoid the free association of terms, the participants were asked to write the concept of "nursing home" three times on their paper (Table 1). The rationale behind this was that if the key concept was not repeated, the participants might write other random words instead of adhering to the key concept.

The WAT was explained to the study participants before the test. They were asked to write, within $30 \mathrm{sec}$, the terms that came to mind that were relevant to the key concept. The 30-sec period had been determined to be the most appropriate time period in previous academic studies. ${ }^{15)}$

In contrast to other studies conducted using the WAT, participants in this study were asked to write several de-

Table 1. Sample of the page format for the data collection tool

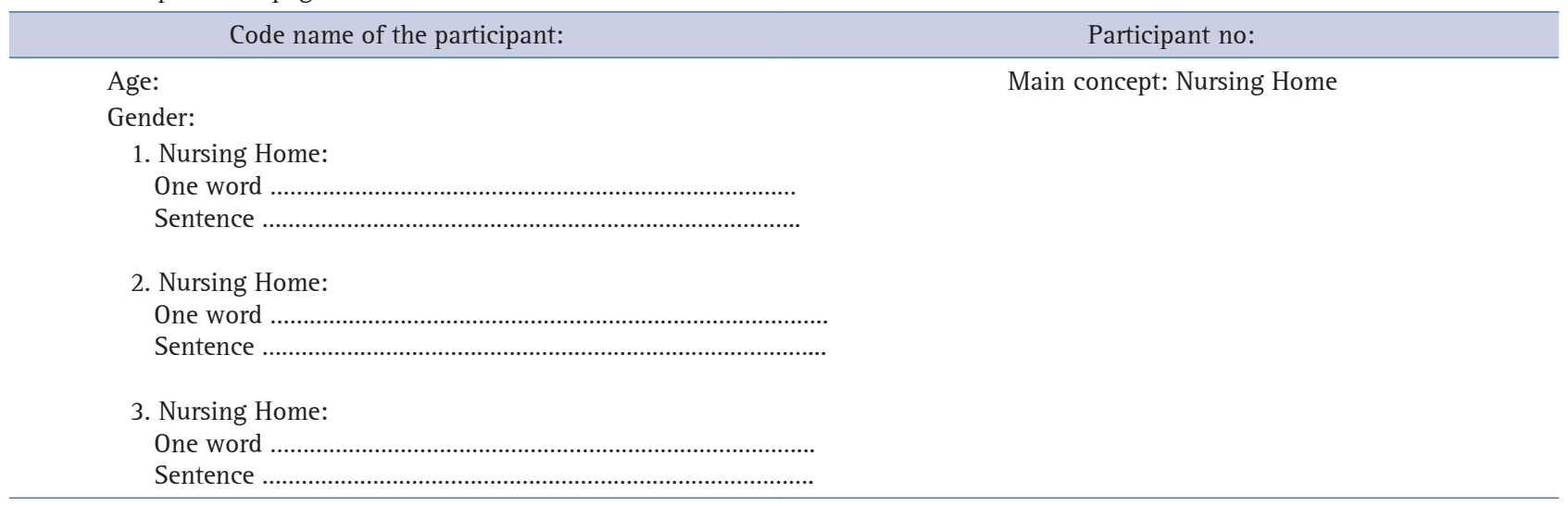


scriptive sentences about each word they wrote. These sentences could be more complex and reflect a higher level of understanding than the words. Therefore, these sentences were evaluated to determine whether they were based on understanding or if they contained misconceptions. The participants were provided additional time to complete this part of the test. The average data collection time was 3-4 $\min$.

The language used in the WAT was Turkish. We first investigated the word-association norms of written responses of the participants. After performing the analysis in Turkish, we translated our findings into English. For trustworthiness of the findings, we consulted a native English speaker.

\section{Data Analysis: Creation of Categories}

The words and sentences obtained from the participants who attempted the WAT test were numbered 1-51 (in the form of participant notes) for analysis. The words that the participants associated with the concept of "nursing home" were arranged in alphabetical order and their frequencies calculated.

Two coders separately encoded the responses and a single code list was created on the basis of the coding consistency. These generated codes were categorized by analyzing the contents together with the words and phrases written by the participants to create five themes. The relationships between the three main words and the sentences describing these words were evaluated. The data obtained from the WAT was organized into word tables and the frequencies were determined. The frequency reflected how many words were repeated for the concept of "nursing home."

When calculating the frequency numbers, the number of frequencies in the data analysis was higher because some participants rewrote the same word more than once (the same word was used sometimes four and up to 10 times). The frequencies were calculated by counting the number of times a word was used in the participants' sentences. In our analysis, not only the three words but also the words used to describe the main word in the sentence were included in the evaluation.

\section{Ethical Consideration}

Approval from the local medical faculty ethics committee was obtained before starting the research (approval date: 26/04/2017, No.: 20.478.486).

\section{RESULTS}

The data were categorized into five main categories depending on the expressions that the terms "nursing home" evoked among the students. The final-year students primarily used more negative expressions. The main categories and their observed frequencies included old age (frequency $[f]=74)$, positive affect emotions ( $f=66)$, negative affect emotions $(f=165)$, loneliness $(f=75)$, and abandonment (f=46) (Fig. 1).

\section{Category 1. Old Age $(f=74)$}

The term "nursing homes" elicited reactions that reflected the concept of old age. It is noteworthy that becoming older was seen as a natural process; however, the participants' responses emphasized the increased difficulties associated with aging as follows.

- "Aging: Starting to struggle with the elimination of daily necessities, encountering obstacles (Participant [P] 2).”

- "Old age: For every human being, the birth process is natural, and so is old age. To accept the process of aging and behaving accordingly is the best job we can do (P 3)."

- "Old age: People who go to nursing homes are generally older people who cannot help themselves in daily life (P 18)."

\section{Category 2. Positive Affect Emotions $(f=66)$}

Students who used positive emotional inferences were more likely to use terms such as "calm/quiet," "positive social environment," "friendship," "a peaceful and safe living place," "sharing," "happiness," "hope," and "socialization."

- "Hope: The desire for happiness and peacefulness for the rest of your life (P 2)."

- "Serenity: The uniquely silent nature of the nursing home reminded me of a peaceful environment (P 5)."

- "Sharing: Older people in the nursing home socialize by sharing things with each other and participating in activities that make them feel good (P 32)."

Some of the descriptions can also be regarded as a positive expression of the students' internal negative meanings.

- "Socialization: Older people may find the social environment they were looking for with their peers in the nursing home that they could not find in their previous homes (P 47)."

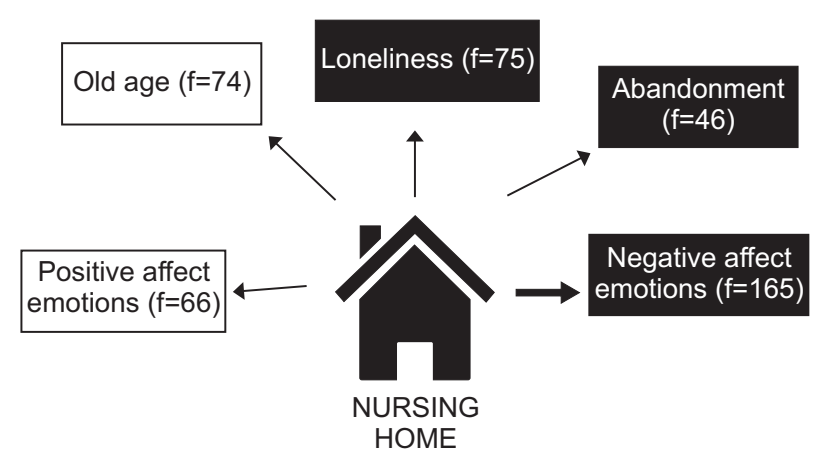

Fig. 1. Students' perceptions of nursing home themes and their frequencies. The rectangular boxes symbolizes themes. The thickness of the arrows is proportional to the frequency of the theme. The white color shows the themes that contain words that describe positive emotions. The black color shows the themes that contain words that describe negative affect. f, frequency. 
- "Friendship: People in the nursing homes form a new family with their peers because of not being close to their families and the new friendships that prosper in the nursing homes (P 32)."

- "The nest of love: They find love and interest in the nursing home that they could not receive from their families (P 51)."

\section{Category 3. Negative Affect Emotions ( $f=165)$}

The statements with negative emotional expressions included "being in need," "expecting death," "last station," "wish for happiness," "need of love," "fear," "anxiety," "sadness," and "missing kids." The most commonly used terms were "need for love," "expecting death," "last station," "not coming to visit," and "the most insecure/distressing period."

- "Thrown away: The love/labor of each mother or father for a child. They raised their children and treated them as their most precious belongings, but the children left their parents to die just because they (the children) or their spouses do not care about their parents' comfort ( $\mathrm{P}$ 51)."

- "Death: Nursing homes: the stop before the grave (P 16)."

- "Waiting: Thinking that children and grandchildren will be visiting; one eye always on the door (P 42)."

Among the negative emotional expressions, "loneliness" and "abandonment" were the most frequently used terms. These two phenomena may be intertwined. However, as observed in the expressions of the students, different perceptions should be emphasized.

\section{Category 4. Loneliness $(f=75)$}

Participants used the term "loneliness" ( $\mathrm{f}=75)$ most frequently in the context of the term "nursing home."

- "Loneliness: The people who are staying seem lonely, which gives the impression that they have lost their spouses and are not wanted by their children (P 14)."

- "Alone: A person staying in a nursing home feels that he is not really in a peaceful home (P 26)."

- "Loneliness: I think that the people there are indirectly forced into loneliness (P 35)."

\section{Category 5. Abandonment $(f=46)$}

Among students in this study, "abandonment" ( $\mathrm{f}=46)$ was the second most common term of the negative emotional expressions associated with the concept of "nursing home." "Abandonment" was often associated with the family of the residents of the nursing home. We could easily evaluate this perception using the following sentences.

- "Abandonment: Our lives change when there is a change from living in a large family to living in a core family, thereby making individuals feel that they are living alone (P 22)."

- "Fidelity: There is sadness in the eyes of all residents of the nursing home, reflecting the abandonment by the family and their sense of disbelief (P 30)."

- "Fidelity: The relatives of the people who stay in nursing homes have died and, therefore, they have to stay in the nursing home. It is our shame (P 27)."

\section{DISCUSSION}

New challenges in the care of older people have begun to emerge as a result of increases in both the general population and the average age. ${ }^{16)}$ It is worthwhile to investigate how nursing homes, born from the needs of modern society, are perceived by final-year students who grew up under two different cultural influences in our country, modernity and traditionalism, ${ }^{17)}$ and to assess their thoughts on this type of institution.

In Turkey, the society has undergone rapid modernization, and transformations have been observed in every sector of social life. ${ }^{18)}$ The modernization of society has resulted in the adoption of a nuclear family structure, a change which has resulted in the establishment of institutions in which older people can receive care services. ${ }^{18,19)}$ Nursing homes, which aim to improve the quality of life of older people for the rest of their lives, are affected by the conflict between modernity and tradition in our country. According to a survey conducted in Turkey of 1,300 aging individuals, $91.7 \%$ of older people stated that they did not want to stay in the nursing home. Among the reasons for not wanting to stay in nursing homes, $50.1 \%$ of the older people stated that they were happy with their family and $21 \%$ stated that their children would not allow them to stay in nursing homes. ${ }^{20)}$

Several reasons could explain the predominantly have negative perceptions about nursing homes among the participating students. The first is the continuation of the conflict between traditional and modern culture in the growing environment: "The unhappiness is caused by relatives who place their ancestors between four walls because of care-taking difficulties" (P 40), "When they do not live with their family/grandchildren, they fight for their lives alone in cold rooms" (P 40). Second, they may have felt that the residents of the nursing home they were visiting were unhappy; "There is sadness in the eyes of all the residents of the nursing home, reflecting the abandonment of their family and their sense of disbelief" (P 27). Third, old age itself can cause negative impressions because, although it is a natural phenomenon, aging is undesirable; "It is a situation in which you cannot look after yourself as you get older, are bedridden, sick, and in need of others" ( $\mathrm{P}$ 7).

\section{Loneliness and Abandonment}

As an individual grows old, family, relatives, and friends, the most important social support elements, are gradually lost. The deaths of valued individuals and separation from the family environment and working life after their children marry and leave home cause older people to feel 
alone and abandoned and to gradually lose social relationships. At this point, the greatest danger is the isolation of older people from social life. ${ }^{21,22)}$ A study of female participants reported that almost all of them felt it inappropriate to confine older people to nursing homes, with the thought that "Our seniors need to be respected." ${ }^{20)}$ In a study conducted among second-year medical faculty students in our country, the majority of students (64.4\%) expressed the sadness of older people regarding the absence of their families and friends after visiting the nursing home. ${ }^{23)}$ The statements made by the students participating in this study were consistent with the results of other studies conducted in our country in which loneliness and abandonment were the major negative reflections.

The loneliness that nursing home residents feel stems from isolation from the family environment. The removal of older people from their own homes and their placement in nursing homes has resulted in the problems of harmony and acceptance. It is difficult for older people to leave a family environment, in which they have spent many years, to adapt to a new environment and live with people they do not know. ${ }^{24)}$

In a study on old age and aging women's perceptions of nursing homes, participants were asked what they thought about living in a nursing home in later life. A 55-yearold woman said, "I don't want to be alone. It's hard to be alone"; another woman who said she would go to the nursing home if necessary said, "I have one son. He also has a family. Now we live separately but do they want to visit me from so far away? I do not know. They will not come if they do not want it. It's hard to look at someone's eyes. It's hard to ask a favor of your son or the bride. I do not want to fight." A 67-year-old woman described a nursing home as "The house of old people and desperate, lonely people"; finally, a 78-year-old woman referred to it as the "place before the grave. The cemetery of the living."

Feelings of loneliness and abandonment are very common among older people. One of the negative effects of staying in nursing homes on aging residents is the feeling of loneliness and abandonment because such situation is considered by older people to be the final phase of life. A significant proportion of older people in the majority of complex societies are lonely and feel abandoned. As reflected by research conducted in our country, the students who participated might be considered a reflection of the society in which they live; although they go through the medical education process, they also associate nursing homes with emotions such as loneliness and abandonment.

\section{Limitations}

First, this study was conducted with a group of volunteer student participants; their perceptions may not reflect those of the entire class at the same time in school. Second, the single facility that students visited might have negatively affected students' perceptions. Third, even if the major expressions of the students are disregarded, the perceptions, interests, and experiences of the researchers might also be impressive factors.

\section{Conclusion}

We believe that young final-year students who will become active physicians will help to determine society's perceptions and thoughts about nursing homes. Their perceptions were influenced by the society in which they lived as well as by the medical education they had received. Such qualitative work with students may provide important information in determining both educational curriculum and social health policies.

\section{CONFLICTS OF INTEREST DISCLOSURES}

The researchers claim no conflicts of interest.

\section{REFERENCES}

1. Tufan I. Ageing and the elderly in Turkey--results of the first age report from Turkey. Z Gerontol Geriatr 2009;42:47-52.

2. Schütz RM. Der alte mensch in gesundheit und krankheit - ethische probleme? In: von Engelhardt and editor. Ethik im alltag der medizin: spektrum der disziplinen zwischen forschung und therapie. 2nd ed. Basel: Birkhäuser Verlag; 1998; p. 259-78. German.

3. Kim KI. Intervention of cardiovascular aging for improving the health status of elderly people. Ann Geriatr Med Res 2017;21:41.

4. Turkish Statistical Institute (TurkStat). 2017 Elderly statistics [Internet]. Ankara: TUIK [cited 2018 Apr 11]. Available from: http:// www.turkstat.gov.tr/PreHaberBultenleri.do?id=27595.

5. United Nations, Department of Economic and Social Affairs, Population Division. World population ageing 2015 [Internet]. New York: United Nations; 2015 [cited 2018 Apr 11]. Available from: https://www.un.org/en/development/desa/population/publications/pdf/ageing/WPA2015_Report.pdf.

6. Hacettepe University Institute of Population Studies, T.R. Ministry of Development and TÜBITAK. 2013 Turkey demographic and health survey. Ankara: Hacettepe University Institute of Population Studies, T.R. Ministry of Development and TÜBİTAK; 2014.

7. Top M, Dikmetaş E. Quality of life and attitudes to ageing in Turkish older adults at old people's homes. Health Expect 2015;18:288300.

8. Öztürk M, Topaloğlu B, Hilton A, Jongerden J. Rural-urban mobilities in Turkey: socio-spatial perspectives on migration and return movements. J Balkan Near East Stud 2018;20:513-30.

9. Republic of Turkey, Ministry of Family Social Policies. Nursing home inventory 2017 [Internet]. Ankara: Republic of Turkey, Ministry of Family Social Policies; 2017 [cited 2018 Apr 11]. Available from: https://www.ailevecalisma.gov.tr/media/6204/bulten-mayis. pdf.

10. Aközer M, Nuhrat C, Say Ş. Expectations regarding old age in Türkiye. Aile ve Toplum 2011;27:103-28.

11. Polat SA, Hira İ. Perception of nursing homes as accomodation units. Int J Hum Sci 2017;14:3250-67. 
12. Shono Y, Ames SL, Stacy AW. Evaluation of internal validity using modern test theory: application to word association. Psychol Assess 2016;28:194-204.

13. Deese J. Form class and the determinants of association. J Verbal Learn Verbal Behavior 1962;1:79-84.

14. Rees CE, Sheard CE, McPherson AC. A qualitative study to explore undergraduate medical students' attitudes towards communication skills learning. Med Teach 2002;24:289-93.

15. Bahar M, Johnstone AH, Sutcliffe RG. Investigation of students' cognitive structure in elementary genetics through word association tests. J Biol Educ 1999;33:134-41.

16. Stone R, Harahan MF. Improving the long-term care workforce serving older adults. Health Aff (Millwood) 2010;29:109-15.

17. Bodur G. Effects of globalization on Turkey [PhD thesis]. Trabzon, Turkey. University of Ka-radeniz Technical University; 2015.

18. Taşci F. Social policies for the old: the cases of Sweden, Germany, UK, and Italy. Çalışma ve Toplum 2010;1:175-202.
19. Kim J, Lee J. Intergenerational program for nursing home residents and adolescents in Korea. J Gerontol Nurs 2018;44:32-41.

20. Şenol D, Erdem S. The old age and the perception of nursing home in elderly women: a qualitative study. Kırkkale Univ J Soc Sci 2017;7:31-50.

21. Gardiner C, Geldenhuys G, Gott M. Interventions to reduce social isolation and loneliness among older people: an integrative review. Health Soc Care Community 2018;26:147-57.

22. Chipps J, Jarvis MA, Ramlall S. The effectiveness of e-Interventions on reducing social isolation in older persons: a systematic review of systematic reviews. J Telemed Telecare 2017;23:817-27.

23. Edirne T, Kutlu M, Ozhan B. Perceptions of second year medical school students regarding ageing and geriatric education: a qualitative study. Turk J Geriatr 2016;19:122-7.

24. Ozyer H. The issue of ageing and old age asylum as a solution. (Dr. Konya Ismail Isik Old Age Asylum Sample) [thesis]. Konya: University of Selcuk; 2016. 